\title{
ANALISIS PLAXIS UNTUK DEWATERING BASEMENT DI TANAH KELEMPUNGAN DAN KEPASIRAN
}

\author{
Angela Kurokawa ${ }^{1}$ dan Chaidir Anwar Makarim²

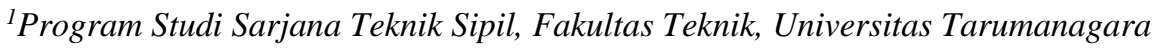 \\ Email : arkurokawa@gmail.com \\ ${ }^{2}$ Program Studi Sarjana Teknik Sipil, Fakultas Teknik, Universitas Tarumanagara \\ Email : chaidir@untar.ac.id
}

\begin{abstract}
ABSTRAK
Galian basement dapat dilakukan dengan beberapa metode disesuaikan dengan kondisi tanah, geometri galian, dan terutama kondisi lapangan, yaitu area tempat dimana akan dilaksanakannya suatu konstruksi bangunan. Salah satu metode yang baik dan akurat untuk digunakan dalam memodelisasikan sifat-sifat tanah yang bervariasi dan material pendukungnya adalah dengan menggunakan metode elemen hingga. PLAXIS 2D merupakan satu dari program-program computer yang dapat menerapkan metode elemen hingga. Penelitian ini dilakukan dengan membandingkan hasil anlisis terhadap kombinasi tanah kelempungan dan kepasiran pada simulasi galian basement dengan program PLAXIS 2D. Analisis dilakukan pada galian yang menggunakan perkuatan secant piles sebagai dinding penahan tanah dan angkur sebagai struktur penunjang. Hasil analisis bertahap terhadap 3 (tiga) kombinasi antara tanah kelempungan (soft, medium, stiff) dan kepasiran (loose, medium, dense) yang dibandingkan dari segi pergeseran dinding dengan nilai terbesar $20,1307 \mathrm{~cm}$, penurunan tanah dengan nilai terbesar $26,75 \mathrm{~cm}$ , dan bidang momen yang terbentuk dengan nilai terbesar 146,28 kNm/m.
\end{abstract}

Kata kunci : galian, analisis bertahap, tanah kelempungan, tanah kepasiran, metode elemen hingga.

\section{PENDAHULUAN}

\section{Latar belakang}

Galian besmen pada tanah yang memiliki muka air tanah yang tinggi memerlukan metode untuk memindahkan air dengan pemompaan, dimana sistem pemompaan tersebut dilakukan untuk mengatasi gaya uplift selama masa kontruksi yang dinamakan groundwater control atau dewatering. Uplift adalah gaya angkay air yang keluar dari dalam pro tanah akibat tekanan pada tanah yang dipadatkan pada proses penggalian besmen. Pekerjaan dewatering mutlak diperlukan sampai bangunan selesai atau berat kontruksi bangunan dapat mengimbangi gaya uplift. Selain itu, dewatering juga diperlukan untuk menanggulangi bila terjadi genangan pada kontruksi besmen atau pondasi, baik akibat air hujan (resipitasi) ataupun rembesan air tanah. Dewatering dioperasikan selama 24 (dua puluh empat) jam selama pekerjaan besmen.

Penyebab kerusakan tanah sekitar ketika pembangunan terjadi adalah saat proses dewatering ini. Proses ini tidak bisa dilakukan pada semua jenis tanah dan pasti akan menghasilkan konsolidasi di tanah sekitarnya. Konsolidasi tanah merupakan penurunan permukaan tanah yang disebabkan tekanan dari permukaan tanah atau memadatnya lapisan tanah di bawahnya karena proses pembebanan tanah. Jika proses ini dilakukan pada tempat yang padat pemukiman maka dikawatirkan akan merusak kontruksi bangunan sekitarnya.

Secara umum, tanah dan batuan dibagi menjadi dua, yaitu: kerikil dan pasir. Pada kerikil ada pembagian divisi, kerikil bersih dan kerikil dengan tanah halus. Begitu pula dengan pasir ada pembagian divisi, yaitu pasir bersih dan pasir dengan tanah halus. Bila pasir dan kerikil halus, maka dinilai dari tipe kesergaman butiran. Sedangkan bila dengan tanah halus, maka dinilai dari kandungan lanau atau lempungnya (Scott, Schoustra, Soil Mechanics and Engineering, 1968). Dengan beragamnya jenis tanah di Jakarta, maka cara pembangunan kontruksi berbeda-beda juga.

Perkembangan teknologi saat ini yang cukup pesat terutama dalam bidang teknologi komputer, menghasilkan banyak software yang dapat mengaplikasikan metode elemen hingga dengan cepat dan baik untuk perhitungan dan analisis permasalahan. PLAXIS versi 8 2D merupakan satu dari program-program komputer yang dapat menerapkan metode elemen hingga.

Dalam program PLAXIS ini, tanah dapat dimodelkan dengan berbagai macam model dimana masing-masing mempunyai karakteristik dan parameter yang berbeda. Untuk itu dalam pemilihan model tanah disesuaikan dengan karakterisik dan sifat-sifat tanah serta dilakukan perhitungan parameter tanah yang dibutuhkan untuk menggantikan 
parameter sesungguhnya dilapangan, sehingga dapat memberikan hasil perhitungan tanah yang mendekati kondisi yang sebenarnya terjadi.

\section{Tujuan Penelitian}

Berdasarkan latar belakang, tujuan dari penelitian ini adalah untuk memperoleh model dan nilai dari pergeseran dinding, penurunan tanah, dan bidang momen pada dinding.

\section{Dewatering}

Secara umum, dewatering merupakan proses pemisahan zat cair dari suatu material padat dengan berbagai metode yang umumnya digunakan. Pada dunia konstruksi, dewatering lebih dikenal sebagai suatu pemisahan atau pengeringan air tanah atau air permukaan di area konstruksi dengan cara dipompa atau diluapkan. Umumnya dewatering dilakukan untuk menurutkan muka air tanah pada area galian, sehingga pekerjaan galian tanah dapat dilakukan. Proses dewatering dijelaskan pada gambar 1.

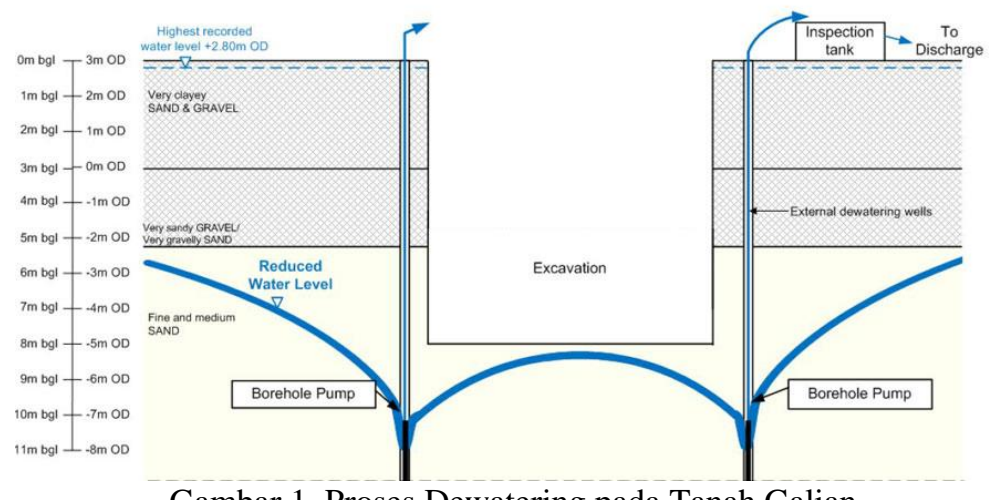

Gambar 1. Proses Dewatering pada Tanah Galian

Selama proses penggalian berlangsung tinggi muka air harus selalu dikontrol. Oleh karena itu, proses dewatering harus dilakukan secara permanen dan terus-menerus sehingga sistem dewatering harus dirancang secara sederhana untuk menghindari control equipment yang susah ataupun dibuthkannya pekerja yang harus mengoperasikan secara terus menerus.

\section{Tanah Kelempungan dan Kepasiran}

Secara umum, tanah diartikan sebagai tumpukan partikel kecil dari disintegrasi batuan, tumbuh-tumbuhan, dan produk manusia. Proses pembentukan tanah secara fisik yang mengubah batuan menjadi partikel yang lebih kecil disebabkan pengaruh erosi, angin, air, es, manusia, dan suhu. Pembentukan tanah secara kimia terjadi oleh pengaruh oksigen, karbondioksida, air yang mengandung asam atau alkali. Kategori besar tanah terdiri dari: partikel berbutir kasar seperti koral (gravel, G), pasir (sand, S), dan partikel berbutir halus yaitu: lanau (silt, M) dan lempung (clay, C). Partikel tanah ini secara langsung dapat dibedakan berdasarkan ukuran butiran yang membentuk.

Tanah kelempungan atau tanah berbutir halus (lanau dan lempung) memiliki struktur yang berbeda. Partikel tanah yang berbentuk dari endapan air tawar atau laut cenderung membentuk "flocculated structure" (struktur endapan). Ciri-ciri struktur ini adalah angka pori besar, kepadatan, dan kadar air. Lempung dan lanau merupakan tanah kohesif yang lebih banyak dipengaruhi oleh plastisitas dan kohesi.

Klasifikasi tanah berbutir halus dijelaskan pada tabel 1 dapat ditentukan berdasarkan nilai parameter plasticity index (PI) dan liquid limit (LL) yang didapat dari test laboratorium kemudian nilai tersebut disesuaikan pada grafik sepert grafik 1 maka didapat jenis tanah berbutir halus. 
Tabel 1. Fine-Grained Soils Classification

\begin{tabular}{|c|c|c|c|}
\hline \multicolumn{4}{|c|}{$\begin{array}{l}\text { FINE-GRAINED SOILS } \\
\text { or more of material is smaller than No. } 200 \text { sieve size.) }\end{array}$} \\
\hline \multirow{3}{*}{$\begin{array}{c}\text { SILTS } \\
\text { AND } \\
\text { CLAYS } \\
\text { Liquid limit } \\
\text { less than } \\
50 \%\end{array}$} & & ML & $\begin{array}{l}\text { Inorganic silts and very fine sands, rock } \\
\text { flour, silty of clayey fine sands or clayey } \\
\text { silts with slight plasticity }\end{array}$ \\
\hline & & $\mathrm{CL}$ & $\begin{array}{l}\text { Inorganic clays of low to medium } \\
\text { plasticity, gravelly clays, sandy clays, } \\
\text { silty clays, lean clays }\end{array}$ \\
\hline & $=$ & OL & $\begin{array}{l}\text { Organic silts and organic silty clays of } \\
\text { low plasticity }\end{array}$ \\
\hline \multirow{3}{*}{$\begin{array}{l}\text { SILTS } \\
\text { AND } \\
\text { CLAYS } \\
\text { Liquid limit } \\
50 \% \\
\text { or greater }\end{array}$} & & MH & $\begin{array}{l}\text { Inorganic silts, micaceous or } \\
\text { diatomaceous fine sandy or silty soils, } \\
\text { elastic silts }\end{array}$ \\
\hline & 身 & $\mathrm{CH}$ & $\begin{array}{l}\text { Inorganic clays of high plasticity, fat } \\
\text { clays }\end{array}$ \\
\hline & 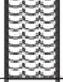 & $\mathrm{OH}$ & $\begin{array}{l}\text { Organic clays of medium to high } \\
\text { plasticity, organic silts }\end{array}$ \\
\hline $\begin{array}{l}\text { HIGHLY } \\
\text { ORGANIC } \\
\text { SOILS }\end{array}$ &  & $\mathrm{PT}$ & Peat and other highly organic soils \\
\hline
\end{tabular}

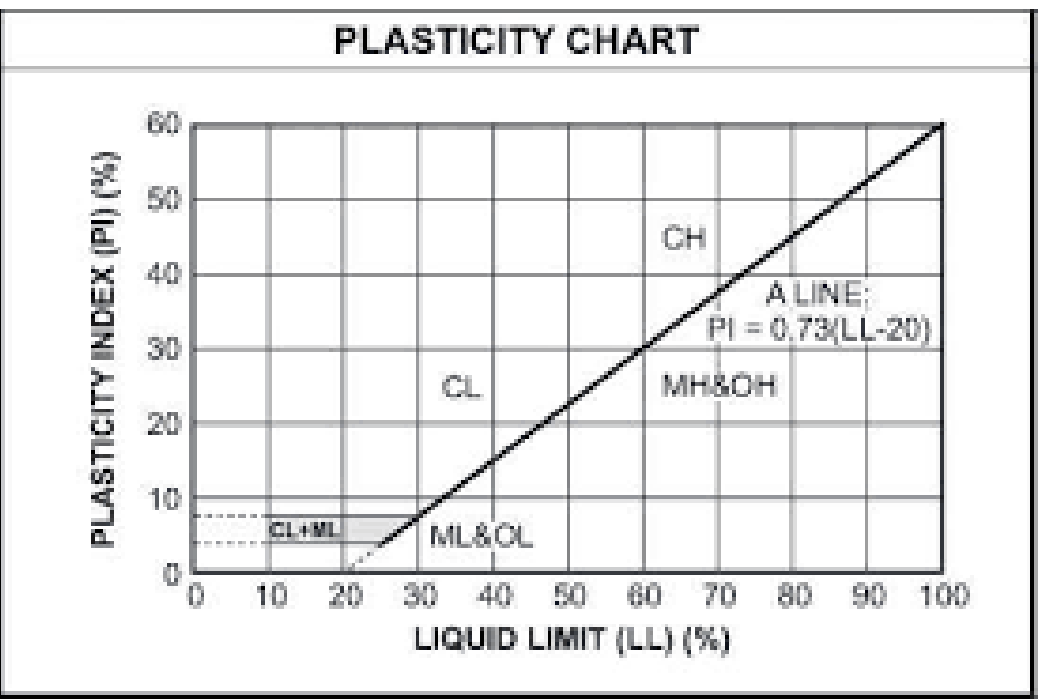

Grafik 1. Grafik Plastisitas untuk Klasifikasi Laboratorium pada Tanah Berbutir Halus

Pada tanah kelempungan, dibedakan menjadi 4 sifat tanah yaitu keras (hard), kaku (stiff), sedang (medium), dan lunak (soft). Identifikasi ini dapat dinilai dari korelasi hubungan antara nilai berat jenis tanah (rsat) dengan unconfined compressive strength $(\mathrm{Qu})$ seperti pada tabel 2 berikut.

Tabel 2. Korelasi empiris antara Nilai N-SPT dengan Unconfined Compressive Strength dan Berat Jenis Tanah Jenuh untuk Tanah Kohesif

\begin{tabular}{|l|l|l|l|}
\hline N-SPT (blows/ft) & Konsistensi & Qu (ton/ft' & rsat $\left(\mathbf{k N} / \mathbf{m}^{\mathbf{3}}\right)$ \\
\hline$<2$ & Very Soft & $<0.25$ & $16-19$ \\
\hline $2-4$ & Soft & $0.25-0.50$ & $16-19$ \\
\hline $4-8$ & Medium & $0.50-1.00$ & $17-20$ \\
\hline $8-15$ & Stiff & $1.00-2.00$ & $19-22$ \\
\hline $15-30$ & Very Stiff & $2.00-4.00$ & $19-22$ \\
\hline$>30$ & Hard & $>4.00$ & $19-22$ \\
\hline
\end{tabular}

Tanah berbutir kasar adalah pasir dan kerikil yang merupakan partikel yang bisa dilihat langsung oleh mata. Tanah ini dipengaruhi oleh ukuran partikel, bentuk partikel, dan berat jenis relatif. Tanah berbutir kasar yang baik adalah susunan butir yang tidak seragam (kecil, sedang, besar), sehingga volume rongga minimum. Kecuali bentuk butir yang bersudut dan permukaan yang kasar meningkatkan stabilitas tanah tersebut. 
Klasifikasi tanah berbutir kasar dijelaskan pada tabel 2.4 dapat ditentukan berdasarkan nilai parameter koefisien keseragaman $(\mathrm{Cu})$, koefisien gradasi $(\mathrm{Cc})$, plasticity index $(\mathrm{PI})$, dan liquid limit (LL) yang didapat dari test laboratorium kemudian nilai tersebut disesuaikan pada tabel 2.5 maka didapat jenis tanah berbutir kasar.

Tabel 3. Coarse-Grained Soils Classification

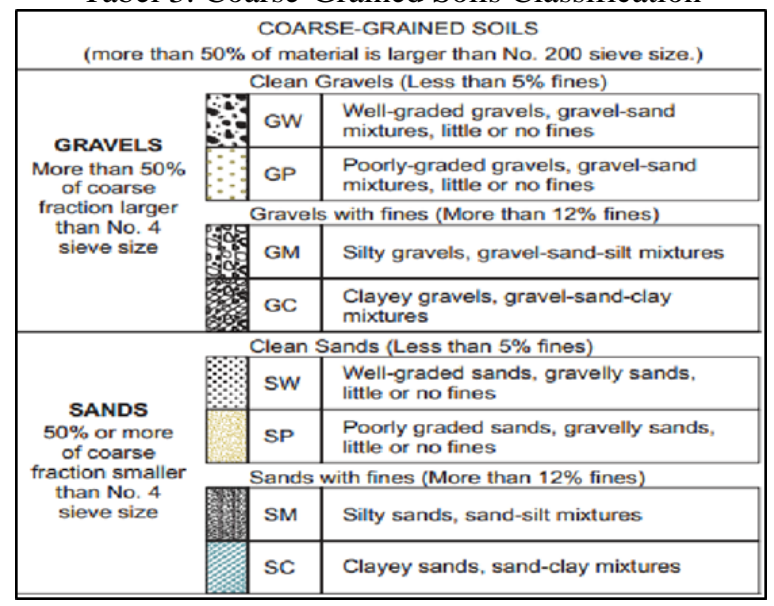

Tabel 4. Laboratory Classification for Coarse-Grained Soils

\begin{tabular}{|c|c|c|c|c|c|c|c|}
\hline \multicolumn{3}{|c|}{ Description } & \multirow{3}{*}{\begin{tabular}{|c|}
$\begin{array}{c}\text { Group } \\
\text { Symbols }\end{array}$ \\
GW \\
\end{tabular}} & \multicolumn{4}{|c|}{ Laboratory Criteria } \\
\hline & & & & $(\%)$ & Grading & Plasticity & Notes \\
\hline \multirow{8}{*}{ 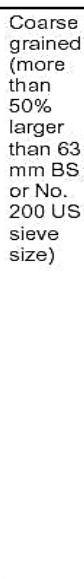 } & \multirow{4}{*}{\begin{tabular}{|l} 
Gravels \\
(more \\
than \\
$50 \%$ of \\
coarse \\
fraction \\
of gravel \\
size)
\end{tabular}} & $\begin{array}{l}\text { Well graded gravels, } \\
\text { with little or no fines }\end{array}$ & & $0-5$ & $\begin{array}{c}\mathrm{C}_{\mathrm{u}}>4 \\
1<\mathrm{C}_{c}<3\end{array}$ & & \multirow{8}{*}{$\begin{array}{l}\text { Dual } \\
\text { symbols if } \\
5-12 \% \\
\text { fines. Dual } \\
\text { symbols if } \\
\text { above A- } \\
\text { line and } \\
4<\mathrm{PI}<7\end{array}$} \\
\hline & & $\begin{array}{l}\text { Poorly graded } \\
\text { gravels, sandy } \\
\text { gravels, with little or } \\
\text { no fines }\end{array}$ & GP & $0-5$ & $\begin{array}{c}\text { Not satisfying } \\
\text { GW } \\
\text { requirements }\end{array}$ & & \\
\hline & & $\begin{array}{l}\text { Silty gravels, silty } \\
\text { sandy gravels }\end{array}$ & GM & $>12$ & & $\begin{array}{l}\text { Below A- } \\
\text { line or } \\
\mathrm{Pl}<4\end{array}$ & \\
\hline & & $\begin{array}{l}\text { Clayey gravels, clayey } \\
\text { sandy gravels }\end{array}$ & GC & $>12$ & & $\begin{array}{c}\text { Above A- } \\
\text { line and } \\
\mathrm{Pl}>7\end{array}$ & \\
\hline & \multirow{4}{*}{\begin{tabular}{|l|} 
Sands \\
(more \\
than \\
$50 \%$ of \\
coarse \\
fraction \\
of sand \\
size)
\end{tabular}} & $\begin{array}{l}\text { Well graded sands, } \\
\text { gravelly sands, with } \\
\text { little or no fines }\end{array}$ & SW & $0-5$ & $\begin{array}{c}C_{4}>6 \\
1<C_{c}<3\end{array}$ & & \\
\hline & & $\begin{array}{l}\text { Poorly graded sands, } \\
\text { gravelly sands, with } \\
\text { little or no fines }\end{array}$ & $\mathrm{SP}$ & $0-5$ & $\begin{array}{l}\text { Not satisfying } \\
\text { SW } \\
\text { requirements }\end{array}$ & & \\
\hline & & Silty sands & SM & $>12$ & & $\begin{array}{l}\text { Below A- } \\
\text { line or } \\
\mathrm{Pl}<4\end{array}$ & \\
\hline & & Clayey Sands & $\mathrm{SC}$ & $>12$ & & $\begin{array}{c}\text { Above A- } \\
\text { line and } \\
\mathrm{Pl}>7\end{array}$ & \\
\hline
\end{tabular}

Pada tanah kepasiran, dibedakan menjadi tiga sifat tanah yaitu lepas (loose), sedang (medium), dan padat (dense). Identifikasi ini dapat dinilai dari korelasi hubungan antara nilai relative density (Dr), nilai N-SPT, tekanan konus (Qc), dan sudut geser dalam $\left(\varnothing^{\circ}\right)$ seperti pada tabel 2.6 berikut.

Tabel 5. Korelasi empiris antara nilai relative density (Dr), nilai N-SPT, tekanan konus (Qc), dan sudut geser dalam $\left(\varnothing^{\circ}\right)$ untuk tanah non-kohesif

\begin{tabular}{c|c|c|c|c}
\hline Kepadatan & $\begin{array}{c}\text { Relative } \\
\text { Density }(\mathbf{D r})\end{array}$ & Nilai N & $\begin{array}{c}\text { Tekanan konus } \\
\mathbf{q c}\left(\mathbf{k g} / \mathbf{c m}^{\mathbf{2}}\right)\end{array}$ & $\begin{array}{c}\text { Sudut geser dalam } \\
\left(\mathbf{O}^{\circ}\right)\end{array}$ \\
\hline Very loose & $<0.2$ & $<4$ & $<20$ & $<30$ \\
\hline Loose & $0.2-0.4$ & $4-10$ & $20-40$ & $30-35$ \\
\hline Medium dense & $0.4-0.6$ & $10-30$ & $40-120$ & $35-40$ \\
\hline Dense & $0.6-0.8$ & $30-50$ & $120-200$ & $40-45$ \\
\hline Very dense & $0.8-1.0$ & $>50$ & $>200$ & $>45$
\end{tabular}




\section{METODOLOGI PENELITIAN}

\section{Metode Pengumpulan Data}

Pada tahap pengumpulan data dilakukan studi literatur pada beberapa buku referensi mengenai tanah, dewatering, PLAXIS, dan aturan-aturan. Pada tahap ini didapatkan parameter-parameter tanah, parameter dinding penahan tanah, parameter angkur, beban yang dipakai, dan kombinasi kondisi lapisan tanah yang akan digali.

\section{Metode Analisis Data}

Metode analisis yang digunakan untuk menganalisa data menggunakan bantuan program PLAXIS 2D yang dapat mensimulasikan lapisan tanah beserta parameternya, simulasi dewatering, dan memberikan hasil berupa pergeseran dinding, penurutan tanah, dan bidang momen beserta gambarnya.

\section{ANALISIS DAN PEMBAHASAN}

\section{Hasil Akhir dengan Kondisi Undrained}

Berdasarkan data-data jenis tanah yang telah dilakukan kombinasi lapisan untuk galian basement 12 meter, dilakukan simulasi galian bertahap. Galian dilakukan setiap 3 meter dan angkur diaktifkan. Maka ditinjau hasil pada pergeseran dinding $(\Delta \mathrm{x})$, bidang momen $(\mathrm{M})$, dan penurunan tanah $(\Delta \mathrm{y})$ sebagai berikut:

Tabel 6. Hasil Analisis Sequential Galian Kondisi Undrained - Kombinasi 1

\begin{tabular}{|c|c|c|c|}
\hline \multirow{2}{*}{ Tahap Galian } & \multicolumn{3}{|c|}{ Sequential } \\
\cline { 2 - 4 } & $\boldsymbol{\Delta x} \mathbf{( c m )}$ & $\mathbf{M}(\mathbf{k N m} / \mathbf{m})$ & $\Delta \mathbf{y}(\mathbf{c m})$ \\
\hline $3 \mathrm{~m}$ & 14.261918 & 169.373325 & 5.2309005 \\
\hline Angkur 1 & 14.261918 & 169.373325 & 5.1394512 \\
\hline $6 \mathrm{~m}$ & 13.796647 & 107.488851 & 5.5401564 \\
\hline Angkur 2 & 13.796647 & 107.488851 & 5.578796 \\
\hline $9 \mathrm{~m}$ & 12.509298 & 38.6032785 & 5.6831589 \\
\hline Angkur 3 & 12.509298 & 38.6032785 & 5.6727828 \\
\hline $12 \mathrm{~m}$ & 11.275255 & -210.793815 & 5.2950128 \\
\hline $\begin{array}{c}\text { Mmax }= \\
\Delta \mathbf{y} \text { max }=\end{array}$ & $146.25 \mathrm{kNm} / \mathrm{m}$ & & \\
\hline
\end{tabular}

Tabel 7. Hasil Analisis Sequential Galian Kondisi Undrained - Kombinasi 2

\begin{tabular}{|c|c|c|c|}
\hline \multirow{2}{*}{ Tahap Galian } & \multicolumn{3}{|c|}{ Sequential } \\
\cline { 2 - 4 } & $\boldsymbol{\Delta x} \mathbf{( c m )}$ & $\mathbf{M}(\mathbf{k N m} / \mathbf{m})$ & $\Delta \mathbf{y}(\mathbf{c m})$ \\
\hline $3 \mathrm{~m}$ & 14.261918 & -39.2700855 & 6.9432602 \\
\hline Angkur 1 & 14.261918 & -39.2700855 & 7.0548572 \\
\hline $6 \mathrm{~m}$ & 13.796647 & -125.18436 & 6.1212388 \\
\hline Angkur 2 & 13.796647 & -125.18436 & 6.2276667 \\
\hline $9 \mathrm{~m}$ & 12.509298 & -15.714081 & 5.2298247 \\
\hline Angkur 3 & 12.509298 & -15.714081 & 5.3186167 \\
\hline $12 \mathrm{~m}$ & 11.275255 & 213.30642 & 4.4326732 \\
\hline Mmax $=$ & $146.28 \mathrm{kNm} / \mathrm{m}$ & \\
$\mathbf{\Delta y} \mathbf{m a x}=$ & $26.75 \mathrm{~cm}$ & &
\end{tabular}


Tabel 8. Hasil Analisis Sequential Galian Kondisi Undrained - Kombinasi 3

\begin{tabular}{|c|c|c|c|}
\hline \multirow{2}{*}{ Tahap Galian } & \multicolumn{3}{|c|}{ Sequential } \\
\cline { 2 - 4 } & $\boldsymbol{\Delta x} \mathbf{( c m )}$ & $\mathbf{M}(\mathbf{k N m} / \mathbf{m})$ & $\Delta \mathbf{y}(\mathbf{c m})$ \\
\hline $3 \mathrm{~m}$ & 14.261918 & -21.4275345 & 8.3648938 \\
\hline Angkur 1 & 14.261918 & -21.4275345 & 8.438462 \\
\hline $6 \mathrm{~m}$ & 13.796647 & -51.719586 & 7.5750219 \\
\hline Angkur 2 & 13.796647 & -51.719586 & 7.6605558 \\
\hline $9 \mathrm{~m}$ & 12.509298 & 2.87293845 & 6.6345116 \\
\hline Angkur 3 & 12.509298 & 2.87293845 & 6.7164699 \\
\hline $12 \mathrm{~m}$ & 11.275255 & 60.197046 & 5.6495066 \\
\hline $\begin{array}{c}\text { Mmax }= \\
\Delta \mathbf{y} \mathbf{m a x}=\end{array}$ & $51.7 \mathrm{kNm} / \mathrm{m}$ & & \\
& $16.27 \mathrm{~cm}$ &
\end{tabular}

\section{Analisis Perbedaan Kombinasi pada kondisi Undrained}

Hasil analisis dengan PLAXIS untuk 3 macam kombinasi tanah dapat dilihat dari deformasi tanah yang terjadi dapat dilihat pada gambar 2 sampai 4 berikut ini:

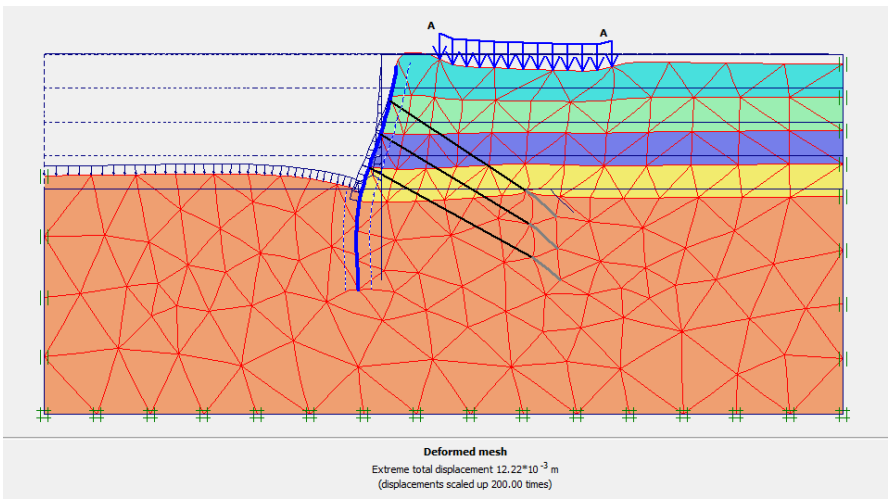

Gambar 2. Deformasi Tanah - Kombinasi 1

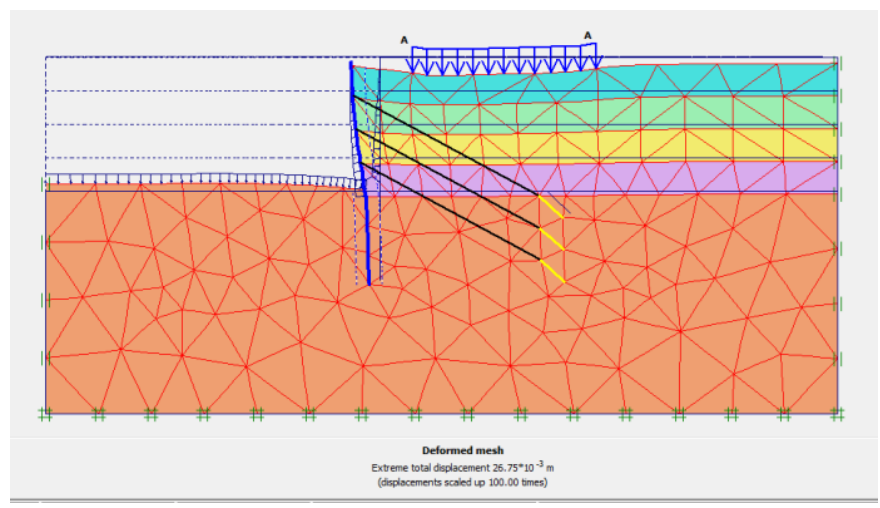

Gambar 3. Deformasi Tanah - Kombinasi 2 


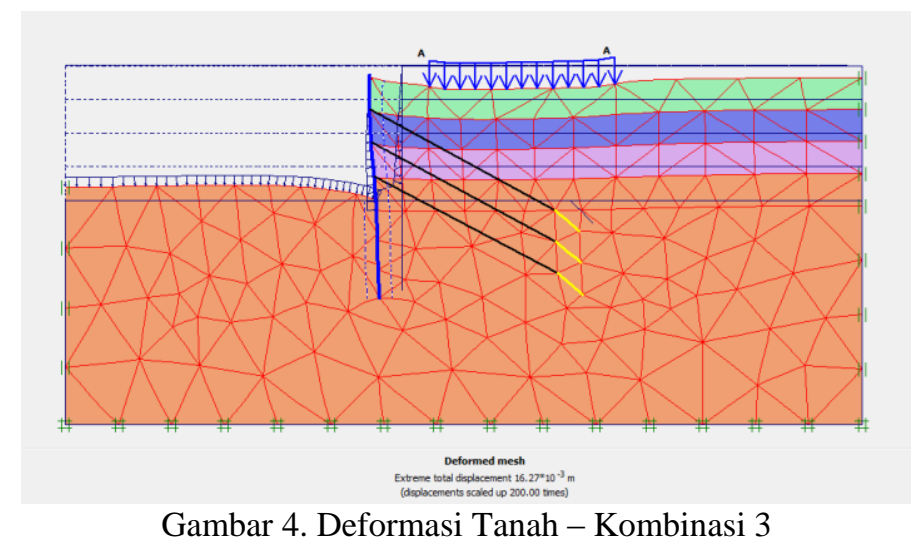

Deformasi tanah terjadi paling besar pada kombinasi-2 dikarenakan tanah di lapisan ke tiga dan empat tidak cukup padat untuk menahan beban tanah yang diatasnya, sedangkan kombinasi-1 dan 2 didasari oleh tanah yang bersifat stiff dan tidak loose. Tetapi kerusakan dinding dan tanah paling kecil terjadi pada kombinasi-3 dimana lapisannya lebih padat.

\section{KESIMPULAN}

Adapun kesimpulan dari hasil analisis dalam penelitian ini yaitu:

1. Analisis sequential dapat menggambarkan elevasi/posisi dimana tanah galian mulai mengalami keruntuhan dan deformasi dinding yang besar, yang dapat berbahaya bagi daerah di sekitar galian.

2. Dari analisis dengan program PLAXIS 2D, analisis terhadap kombinasi tanah galian tidak memberikan perbedaan dari segi faktor keamanan.

3. Analisis dengan kombinasi 2 dan 3 pada simulasi galian basement 12 meter (dengan secant pile dan tieback anchor), tidak memiliki perbedaan hasil deformasi tanah, deformasi dinding, dan bending moment yang signifikan. Sehingga seharusnya analisis dapat dilakukan dengan kombinas 3 saja yang memiliki nilai lebih kecil karena kombinasi tanah berupa medium clay-stiff clay-medium gravel-dense gravel dimana kombinasi ini lebih kuat dan padat.

4. Analisis dengan kombinasi 1 pada simulasi galian basement 12 meter (dengan secant pile dan tieback anchor), memiliki perbedaan hasil deformasi tanah, deformasi dinding, dan bending moment yang signifikan dengan kombinasi 2 dan 3. Kombinasi ini sangat buruk karena tidak didasarkan pada tanah yang keras, yaitu: soft claymedium clay-stiff clay-loose gravel. Keadaan dinding yang rusak struktural dan penuruan tanah yang mengarah keluar akan mengakibatkan kerusakan pada bangunan tetangga yang sangat parah.

\section{DAFTAR PUSTAKA}

Bowless, J.E. and Hainim, J.K. Sifat-sifat Fisis dan Geoteknis Tanah. Jakarta : Penerbit Erlangga, 1991. British Stamdard. Code of Practice for Ground Anchorages. Bsi standards publicatios.

Budhu, M. and J.E. Bowless. Soil Parameters and Correlation. New York : John Wiley \& Sons. 2015.

Das, Braja M., Mekanika Tanah : Prinsip - Prinsip Rekayasa Geoteknis, Jilid 1, Jakarta : Erlangga, 1995

Das, Braja M., Mekanika Tanah : Prinsip - Prinsip Rekayasa Geoteknis, Jilid 2, Jakarta : Erlangga, 2002

Firmansyah, Irawan, Ground Anchor Design. Jakarta: Seminar Geo-talk. 2015.

Lambe, T. William, dan Robert V. Whitman, Soil Mechanics : The classic, comprehensive guide to the physics of soil, John Wiley \& Sons, 1969

Scott, Ronald, dan Jack Schoustra, Soil Mechanis and Engineering : a systematic theory-to-practice approach to the mechanis and engineering of soils, USA : McGraw-Hill, Inc., 1968

Tjie-Liong, Gouw, “Uji Coba Pemompaan dan Permasalahan Dewatering”, PT Limara Engineering, Universitas Tarumanagara, 1994

Wesley, L. D., Mekanika Tanah. Jakarta : Badan Penerbit Pekerjaan Umum, 1977 
